\title{
Desenvolvimento de software para o planejamento da arborização urbana ${ }^{(1)}$
}

\author{
PAULO ROBERTO CORREA LANDGRAF(2), PATRICIA DUARTE DE OLIVEIRA PAIVA ${ }^{(3)}$, \\ LEANDRO APARECIDO DOS REIS ${ }^{(4)}$
}

\begin{abstract}
RESUMO
Em função das informações necessárias ao adequado planejamento e manejo da arborização, é indispensável que estes estejam organizados por meio de um sistema computadorizado, com o objetivo de elaborar um software para o planejamento da arborização urbana, de acordo com os diferentes locais e situações de plantio, permitindo realizar, por meio deste, a indicação de espécies corretas para a arborização urbana. Para a obtenção dos dados, foram realizados levantamentos das características das espécies vegetais, gerando dados para registro no sistema. Destas espécies, foram registradas características como: altura, diâmetro de copa, altura da bifurcação, folhas, flores (cor e época de floração), tipo de raiz, tipo de tronco, sanidade, entre outras. O software desenvolvido permite a seleção de espécies apropriadas para um determinado projeto, oferecendo opções ao usuário para escolha. O programa gera consultas e relatórios com os dados conforme a característica do projeto, sendo possível a impressão dos dados das árvores escolhidas, tais como: nome comum, nome cientifico, família, imagem e características da espécie.
\end{abstract}

Palavras-chave: meio urbano, árvores, gerenciamento.

\section{ABSTRAT \\ Development of a software for planning urban arborization}

\begin{abstract}
Adequate planning and handling of street arborization must be organized by means of a computerized system. A software was developed to indicate the appropriate species for urban arborization according to different locations and planting situations. The characteristics of vegetal species were surveyed for the obtainment of data to be registered into the system, such as height, cup diameter, height of the furcation, leaves, flowers (color and flowering time), root type, trunk type, tree health, and so forth. The software allows the selection of species which are appropriate for a certain project, offering options for the user. The program generates consultations and reports with project-related data which can be printed, such as common name, scientific name, family, image, and species characteristics.
\end{abstract}

Keywords: Urban environment, trees, management

\section{1- INTRODUÇ̃̃̃O}

Tradicionalmente, as cidades surgiram e se desenvolveram valorizando os espaços construídos em detrimento ao espaço natural. O domínio do homem sobre a natureza fica claramente explícito nas cidades como um grande espaço aberto desprovido do verde, sendo este substituído pelas construções e interferências arquitetônicas. $\mathrm{O}$ verde vem sendo observado, com maior frequência, apenas nos quintais de áreas particulares (GOUVÊA, 2001).

A arborização urbana planejada proporciona efeitos paisagísticos relevantes ao meio urbano e também à população. As árvores fornecem inúmeros benefícios ao meio ambiente, refletindo na qualidade de vida e humanização das cidades. As árvores amenizam a temperatura com a sombra de suas copas e umidificam o ar por meio da transpiração das folhas; retêm partículas de poeira e de poluição na sua copa; purificam o ar produzindo oxigênio; reduzem os ruídos e servem de barreira contra os ventos; evitam a erosão, diminuindo o impacto da água da chuva na superfície do solo e fixando a terra com suas raízes; ordenam a paisagem urbana; fornecem abrigo e alimento à avifauna; transmitem bem-estar e equilíbrio psicológico ao homem pelas cores de suas folhas, flores e frutos.

De acordo com FARAH (1999), a introdução consciente de árvores nos espaços públicos aconteceu inicialmente na Europa, por volta do século XVIII. Segundo SEGAWA (1996), a prática de plantio de árvores iniciou-se com os belgas de Antuérpia, durante a prosperidade do século XVII, que mantinham áreas ornamentadas com árvores nas laterais das catedrais, e esse espaço, era valorizado por habitações de grandes mercadores europeus, ficando conhecido por Plate Verde ou Groenplaats. Somente a partir do início do século XVII, a vegetação começa a ser introduzida no espaço público urbano com objetivos estético-culturais, traduzidos pelo pensamento neoclássico e a posterior preocupação romântica com o sublime (GOUVEA, 2001).

Atualmente na arborização urbana, o planejamento tem sido muito evidenciado, dada a sua grande importância, nas

\footnotetext{
(1) Recebido em 10 de maio de 2013 e aceito para publicação em 30 junho de 2013.

${ }^{(2)}$ Engenheiro Agrônomo e Eng. Florestal, Doutor. Universidade José do Rosário Vellano - UNIFENAS - Faculdade de Agronomia - Rodovia MG 179 KM 0 - Alfenas - MG CEP 37.130-000.

(3) Engenheira-Agrônoma, Doutora. Departamento de Agricultura, Universidade Federal de Lavras, Caixa Postal 3037, 37200-000, Lavras, Minas Gerais, Brasil. patriciapaiva@dag.ufla.br;

(4) Engenheiro Agrônomo. Universidade José do Rosário Vellano - UNIFENAS - Faculdade de Agronomia - Rodovia MG 179 KM 0 - Alfenas -MG CEP

37.130-000.1eandrox6@hotmail.com
} 
discussões sobre os problemas e diretrizes das cidades e na busca de melhor qualidade de vida para os cidadãos.

O planejamento correto exige que se tenha um levantamento dos locais a serem arborizados, como também daqueles que necessitam ser complementados ou adaptados. O local deve ser bem estudado, levando-se em conta suas necessidades, limitações, tipo predominante de ocupação, características do tráfego, largura das ruas, tipo de solo e características ambientais. Além disso, há necessidade de compatibilizar a arborização com o sistema elétrico, abastecimento de água, esgoto, sinalizações e edificações. $\mathrm{O}$ cadastramento e o controle das ruas e praças possibilitam maior eficiência e agilidade na implantação e manutenção da arborização urbana. Contudo, dentro deste cenário, o planejamento e a manutenção adequada da arborização urbana tornam-se um dos grandes desafios aos gestores municipais.

RODRIGUES et al. (2002) descrevem os problemas causados pelo confronto do plantio de árvores inadequadas com equipamentos urbanos, como fiações elétricas, encanamentos, calhas, calçamentos, muros, postes de iluminação, etc. Estes problemas são muito comuns e causam, na maioria das vezes, um manejo inadequado e prejudicial às árvores. É comum ver árvores podadas drasticamente e com muitos problemas fitossanitários, como presença de cupins, brocas, outros tipos de patógenos, injúrias físicas como anelamentos, caules ocos e podres, galhos lascados, etc.

A arborização urbana sem planejamento pode provocar curto-circuito em redes aéreas, rompimento de cabos condutores, interrupção no fornecimento de energia, queima de eletrodomésticos, comprometimento da iluminação pública e riscos para os transeuntes, além de interferir e conflitar com outros bens e serviços urbanos, tais como: placas de sinalização, redes de gás, de água e de telefone, edificações e rede viária (CEMIG, 2001). SILVA et al. (2008) relatam que a situação da arborização viária nas grandes cidades brasileiras é muito precária em decorrência do planejamento inadequado.

Segundo ROSO (1994), um dos grandes problemas enfrentados na arborização urbana é a escolha de espécies que não apresentam condições ideais de compatibilização com os espaços disponíveis, tanto em relação ao diâmetro da copa e altura como quanto ao sistema radicular. Este último diz respeito a conflitos com redes subterrâneas e passeio público. Se, em relação à parte área, problemas com os fios às vezes podem ser resolvidos com podas, no que se refere às raízes, as interferências podem trazer dificuldades, uma vez que o corte do sistema radicular pode provocar desequilíbrio do vegetal, podendo culminar com a queda das árvores.

São fatores limitantes no processo de arborização, conforme relata DEMATTÊ (1997): largura das ruas, largura das calçadas, recuo das casas, presença de redes subterrâneas e a presença de fios aéreos da rede elétrica. Ruas com menos de $7 \mathrm{~m}$ de largura, casas sem recuo e calçadas com menos de $3 \mathrm{~m}$ de largura não comportam arborização. No caso de ruas com canteiro central, este pode ser arborizado em função de sua largura. Em canteiros com largura inferior a $1,50 \mathrm{~m}$, recomenda-se o plantio de arbustos ou palmeiras. Em canteiros maiores que 1,50m, podem ser plantadas as árvores de tamanho adequado à largura das pistas laterais.

De acordo com OLIVEIRA e CASTELO BRANCO (1996), a ausência de um planejamento que acompanhe e condicione o crescimento das cidades, substituindo e repondo as áreas verdes urbanas, conduz a uma situação terrível na maioria das cidades, situação que tende a se agravar, pelas constantes agressões às áreas de preservação ambiental.

Antes do planejamento da arborização, é necessário hierarquizar os espaços livres de uma cidade quanto à sua tipologia e categoria para que o resultado seja maximizado dentro da área urbana (CAVALHEIRO, 1994). MILANO e DALCIN (2000) relatam que os planos diretores para a arborização devem definir o plantio de forma segmentada, fazendo com que as árvores sejam diversificadas em idade e espécie.

Em função do grande volume de informações necessárias ao adequado manejo da arborização, é indispensável que estes estejam organizados por meio de um sistema computadorizado (TAKAHASHi, 1992).

Um banco de dados para o cadastro total das árvores de Maringá (PR) foi elaborado por TAKAHASHI (1992). Segundo GODFREY (2001), existem muitas vantagens em cadastrar os dados das árvores urbanas em banco de dados georreferenciados e poder consultá-los em programa de geoprocessamento. $\mathrm{O}$ autor apresenta como vantagens: realização de mapeamento das áreas e árvores permitindo consultas visuais rápidas; facilidade de encontrar a localização de uma árvore quando ela está representada em um mapa para indicar sua localização; possibilidade de consulta de dados da população arbórea; possibilidade de relacionamento de dados e informações entre árvores.

FREIRE et al. (1994), MARTINS (1994), CÂMARA E MONTEIRO (2000) e ADAM et al. (2001) também descreveram a utilização da geoinformação para inventário de espécies arbóreas e outras finalidades ambientais para as cidades de Belo Horizonte (MG), Recife (PE), Florianópolis (SC) e São Sebastião (SP), respectivamente.

O custo de implantação de um sistema de gerenciamento e controle informatizado, conforme relatam ADAM et al. (2001), é significativamente menor que o custo futuro de modificação dos espaços públicos devido à falta de planejamento. Entendeu-se também que, mesmo realizando-se um grande trabalho de campo, com cadastro da vegetação das praças e áreas públicas, e os resultados dispostos em tabelas em papel guardadas em arquivos de armário, estes resultados, em alguns anos, estariam obsoletos e poucos saberiam como estão as espécies vegetais e o real estado de conservação das praças, pois a atualização e manipulação destes arquivos seria difícil e demorada, justificando a implantação da geoinformação.

Apesar de existirem vários softwares para cadastro, não existe até o momento um pacote computacional direcionado para o planejamento da arborização urbana.

Objetivou-se elaborar um software para o planejamento da arborização urbana, de acordo com os diferentes locais e situações de plantio, permitindo realizar, com uso deste, a indicação de espécies corretas para a arborização urbana. 


\section{MATERIAL E MÉTODOS}

Para realização deste trabalho, foram selecionadas espécies arbóreas com características desejáveis para a arborização urbana, ou seja, porte, formato e densidade de copa, ausência de odores, desenvolvimento precoce, resistência a podas, exigência de cultivo, rusticidade, adaptabilidade às condições ambientais locais, florescimento, tamanho do fruto, resistência a pragas e doenças, folhagem permanente, raiz pivotante, ausência de espinhos, ausência de princípios tóxicos e efeitos paisagístico.

O software foi desenvolvido usando a linguagem Microsoft Visual Base 5.0, sendo a base de dados usada para armazenar as informações Microsoft Access 97. A base de dados é protegida contra acessos indevidos, podendo ser acessada apenas por meio da interface do próprio software.

$\mathrm{O}$ software pode ser instalado em qualquer computador que tenha o Sistema Operacional Windows XP ou superior. Este software pode ser útil para as prefeituras municipais, empresas de planejamento, empresas de paisagismo e para profissionais da área, resolvendo o problema das espécies de árvore para o local correto.

\section{RESULTADOS E DISCUSSÃO}

Com o uso do pacote, podem-se selecionar as espécies apropriadas para um determinado local, levando em conta as características da situação e oferecendo opções ao usuário para escolha (Figura 1).

O software poderá gerar consultas e relatórios com os dados conforme a característica do projeto, sendo possível a impressão dos dados das árvores escolhidas, tais como: nome comum, nome cientifico, família, imagem e características da espécie. De posse das características locais, como largura da rua, largura de calçada, presença de fiação aérea, presença de poste de iluminação e localização da garagem, será feita uma entrada no pacote computacional elaborado, onde se pretende encontrar a espécie arbórea adequada para cada situação local.

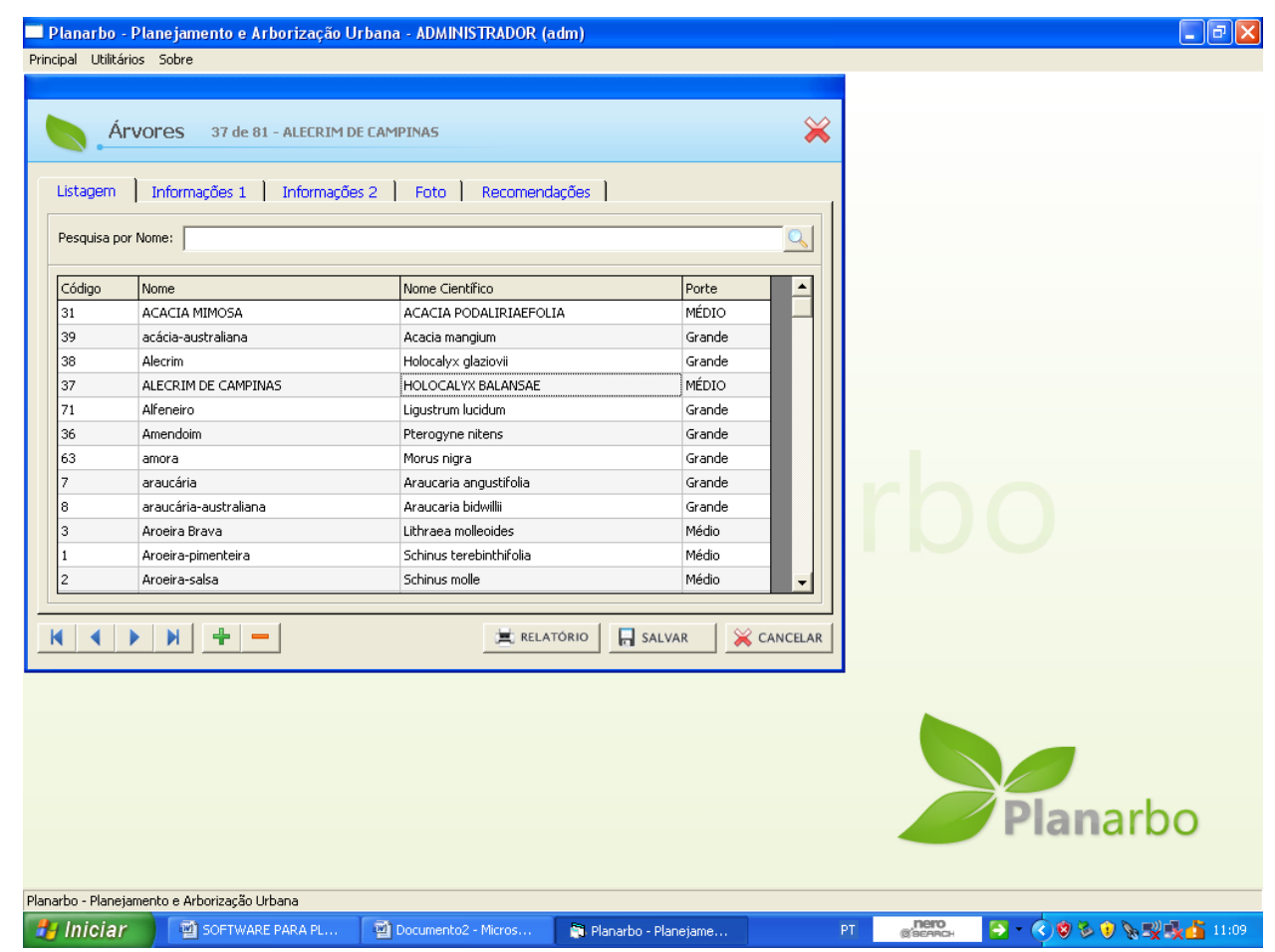

Figura 1. Listagem de espécies arbóreas existentes no sistema.

O usuário poderá incluir dados para aumentar as opções na busca por uma árvore mais indicada ou excluir as árvores do sistema, dependendo das necessidades ou da localização (Figura 2).

$\mathrm{O}$ modelo de banco de dados relacional possui a capacidade de lidar com grandes volumes de informações, eliminando dados redundantes (KAUFELD, 1996). No modelo relacional, existe a possibilidade de elaboração de um relacionamento lógico entre as informações referentes à espécie e aquelas referentes ao indivíduo, evitando-se a necessidade da repetição de informações e agilizando as consultas feitas às duas fontes de dados. 


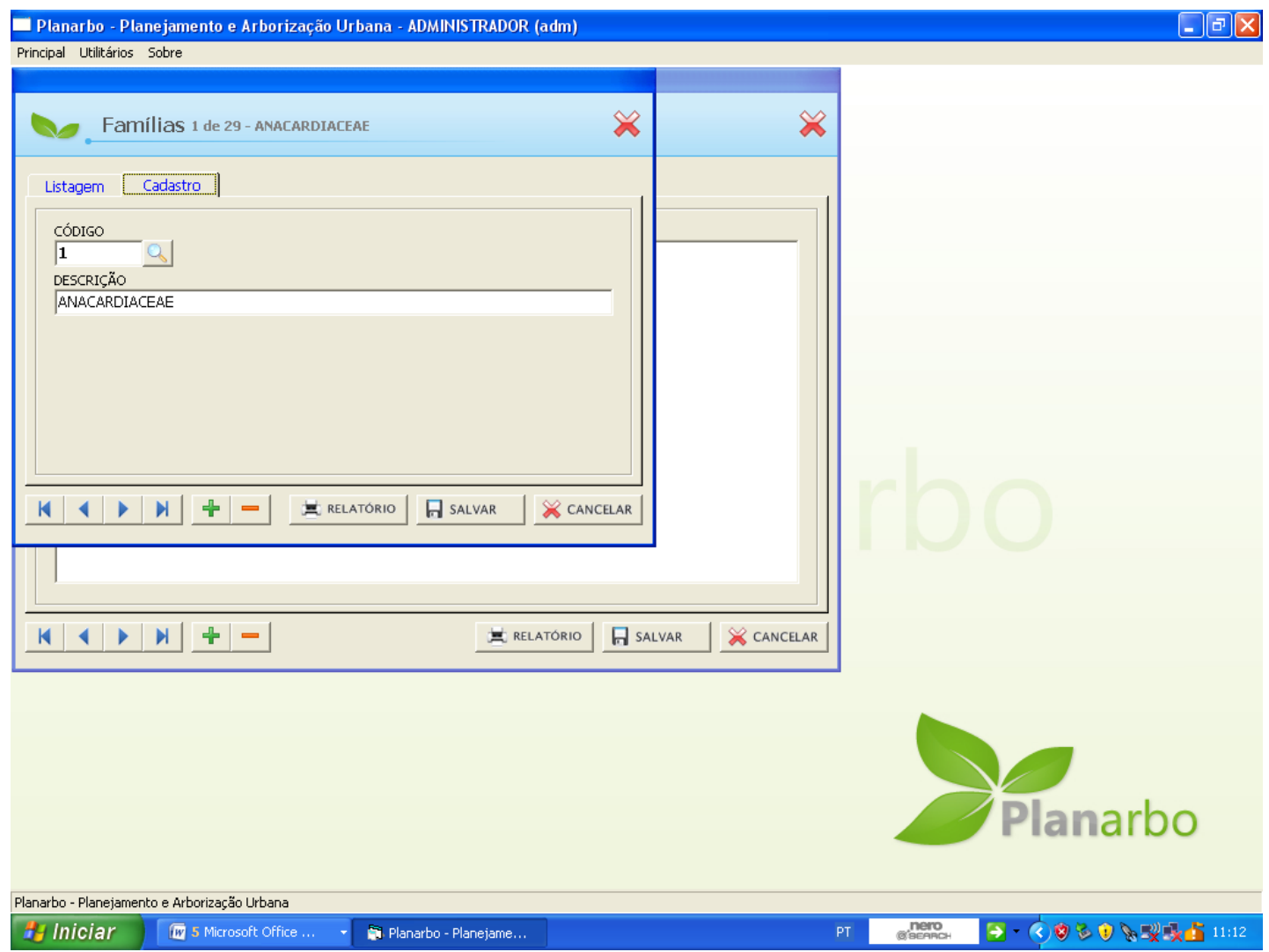

Figura 2. Inclusão de informações pelo usuário.

Na prática, conforme relata DALCIN (1994), o modelo relacional oferece os seguintes benefícios: simplicidade e uniformidade (o modelo relacional é compacto); independência dos dados físicos; interfaces de alto nível para usuários finais; visões múltiplas dos dados; melhoria na segurança dos dados; redução significativa do tempo gasto na manutenção da base de dados; e possibilidade de expansão devida wà flexibilidade do sistema.

\section{CONCLUSÃO}

O programa indica a espécie arbórea conforme as características desejadas, sendo possível a impressão dos dados das árvores escolhidas, tais como: nome comum, nome cientifico, família, imagem e características da espécie.

\section{AGRADECIMENTOS}

Os autores agradecem as FAMPEMIG pelo apoio.

\section{REFERÊNCIAS}

ADAM, E.; GUEDES JÚNIOR, A.; HOCHHEIM, N. Geoprocessamento para o inventário das espécies arbóreas na região de Florianópolis. GISBRASIL 2001, Curitiba. Anais... Curitiba: Fator GIS, 2001. (CD-ROM).

CÂMARA, G.; MONTEIRO, A.M. Geotecnologias em um novo paradigma de desenvolvimento. Seminário sobre indicadores de sustentabilidade. NEPO/UNICAMP, 2000. 25p.

CAVALHEIRO, F. Arborização urbana: planejamento, implantação e condução. In. ENCONTRO NACIONAL DE ARBORIZAÇAO URBANA, 5., São Luis, 1994, Anais... São Luís: Sociedade Brasileira de Arborização Urbana, 1994. p.227-231.

CEMIG. Manual de arborização urbana. Belo Horizonte: Cia de Energia de Minas Gerais, 2001. 42 p.

DALCIN, E. C. A informática no inventário e monitoramento da arborização urbana. In: CONGRESSO BRASILEIRO SOBRE ARBORIZAÇÃO URBANA, 2., 1994, São Luís. Anais... São Luís: Sociedade Brasileira de Arborização Urbana, 1994. p. 201-206.

DEMATtÊ, M. E. S. P. Princípios do paisagismo. Jaboticabal: Funep, 1997. 104p.

FARAH, I. M. C. Arborização urbana e sua inserção no desenho urbano. Boletim Informativo da Sociedade Brasileira de Arborização Urbana, v.7, n.3, p.6, 1999.

FREIRE , F. J. et al. Cadastramento das árvores públicas da cidade do Recife utilizando o sistema de informações geográficas (GIS). In: CONGRESSO BRASILEIRO SOBRE ARBORIZAÇÃO URBANA, 2., 1994, São Luís. Anais... São Luís: Sociedade Brasileira de Arborização Urbana, 1994. p. 431-436. 
GODFREY, C. G. GIS \& GPS in urban forestry. City Trees, v.37, n.3, p.14-16, 2001.

GOUVÊA, I. Cobertura vegetal urbana. Revista Assentamentos Humanos, Marília, v.3, n.1, p.17-24, 2001

KAUFELD, J. Access 95 para Windows para leigos: um manual para novos usuários. LUDEMIR, J. (tradutor). São Paulo: Berkeley Brasil, 1996. 353p.

MARTINS, S.V. Monitoramento da arborização de ruas de Belo Horizonte. In: CONGRESSO BRASILEIRO DE ARBORIZAÇAO URBANA, 2., 1994, São Luís. Anais... São Luís: SBAU, 1994. p.421-430.

MILANO, M. S.; DALCIN, E. C. Arborização de vias públicas. Rio de Janeiro: Light, 2000. 226p.

OLIVEIRA, P.M.S. de, CASTELO BRANCO, A. Arborização do Município de São Paulo. In: CONGRESSO BRASILEIRO DE ARBORIZAÇAO URBANA, 3., 1996 Salvador, Anais... Salvador, 1996, p.177-183.
RODRIGUES, C. A. G. et al. Arborização e produção de mudas de essências florestais nativas em Corumbá, MS. Corumbá: EMBRAPA, 2002. 27p.

ROSO, A. L. Influência do sistema radicular de árvores urbanas na pavimentação em vias públicas. In. CONGRESSO BRASILEIRO DE ARBORIZAÇAO URBANA, 3.,1994. São Luís. Anais... São Luís: Sociedade Brasileira de Arborização Urbana, 1994. p.347-352,

SEGAWA, H. Ao amor do público: jardins no Brasil. São Paulo: Studio Nobel, 1996. 240p.

SILVA, L. F. da; VOLPE-FILIK, A.; LIMA, A. M. L. P.; SILVA FILHO, D. F. da. Análise da arborização viária em dois bairros de Americana (SP). Revista Brasileira de Horticultura Ornamental, v.14, n.2, 2008.

TAKAHASHI, L. Y. Monitoramento e informatização da administração e manejo da arborização urbana. In: CONGRESSO BRASILEIRO SOBRE ARBORIZAÇÃO URBANA, 1., 1992, Vitória. Anais... Vitória: PMV/ SMMA, 1992. p.119-124. 